\title{
DOSSI|Ê
}

Sociologias, Porto Alegre, ano 10, no 20, jul./dez. 2008, p. 20-47

\section{Ambivalência e Medo: faces dos riscos na Modernidade}

\section{Resumo}

No diagnóstico da modernidade, incerteza e insegurança - e portanto o medo - são elementos presentes. Partindo dessa constatação, este trabalho tem por objetivo descrever os efeitos ambivalentes do medo sobre a sociedade contemporânea. Nesta tentativa, busca-se 0 apoio de diversas teorias sociais que, embora não enfoquem o medo, mostram de certa forma os riscos constantes do processo de modernização. Por outro lado, isso permite separar a crítica social que ainda tenta continuar pensando a modernidade com base nas premissas conceituais da razão ocidental, de uma outra, que por sua própria fadiga proclama sua autodestruição. Entende-se aqui que se despedir da razão e considerar o movimento autônomo da modernidade é fazer surgir um processo que apenas garante a modernização do medo.

Palavras-chave: Modernidade. Risco. Medo.

Apenas o ente em que, sendo, está em jogo seu próprio ser, pode temer. 0 medo (temor) abre esse ente no conjunto de seus perigos (riscos), no abandono a si mesmo.

Heidegger

\footnotetext{
* Doutor pelo NAEA/U FPA, Prof. da Faculdade de Ciências Sociaise do Programa de Pós-Graduação em Ciências Sociais (PPGCS) da U FPA. Integra a linha de Pesquisa violência e Não-Violência nos Processos Sociais.

** D outor pela U NICAM P, Prof. da Faculdade de Ciências Sociaise do Programa de Pós-Graduação em Ciências Sociais (PPGCS) da U FPA. Integra a linha de Pesquisa violência e Não-Violência nos Processos Sociais.
} 


\section{Introdução}

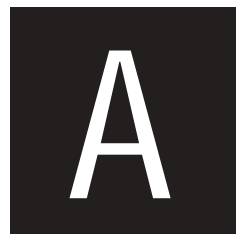

crescente potencialidade de destruição que a humanidade engendrou sobre ela mesma tem despertado ainda muito pouco interesse por uma reflexão do medo. Jean Delumeau (1989), em seu livro História do M edo no O cidente, indaga-se: por que esse silêncio prolongado sobre o papel do medo na História? Pode-se até acreditar que se deve ao fato de o medo estar relacionado à covardia e à vergonha, devendo, por isso, ser escondido. Mas o teórico da sociedade não pode ter medo dos medos sociais. Parece mais fácil enterrar o medo dentro de nós e hipocritamente ressaltar feitos heróicos. 0 ra, o medo, como veremos mais adiante, é inerente à nossa natureza: é um sentimento que nos perturba, que traz inquietação, sobressaltos, que exige providências e o cálculo de riscos, enfim, ele faz parte do cotidiano. M esmo que o medo possa ser visto por esse ângulo, a incerteza e a insegurança são fatores que provocam medo contínuo e, por conseguinte, mal-estar permanente.

No diagnóstico da modernidade, incerteza e insegurança - e portanto 0 medo - são elementos presentes. Partindo dessa constatação, este trabalho tem por objetivo descrever os efeitos ambivalentes do medo sobre a sociedade contemporânea. Nesta tentativa, busca-se 0 apoio de diversas teorias sociais que, embora não enfoquem o medo, mostram de certa forma os riscos constantes do processo de modernização. Por outro lado, isso permite separar a crítica social, que ainda tenta continuar pensando a modernidade com base nas premissas conceituais da razão ocidental, de uma outra, que, por sua própria fadiga, proclama sua autodestruição. Entende-se aqui que se despedir da razão e considerar o movimento autônomo da modernidade é fazer surgir um processo que apenas garante a modernização do medo. 


\section{A Busca da Autocertificação}

As narrativas da modernidade apontam para um sentimento de aventura. U ma nova experiência de tempo e espaço vai, aos poucos, conformando a modernidade, uma nova cultura, que rompe com as tradições, institui novos laços sociais. Na modernidade, o mercado e o Estado assumem de maneira estrita a função de princípio estruturante da sociedade. Por meio do mercado, os indivíduos exercem a "liberdade" econômica: os indivíduos, de forma fragmentada, defendem os seus interesses. $\mathrm{Na}$ esfera da política, a representação tornou-se a forma mais eficiente de mediação, com o Estado assumindo o monopólio legítimo da normatização das relações sociais. A impessoalidade passou a ser o princípio sobre o qual assenta a intervenção normativa. A modernidade, assim pensa Habermas (1990: 18), "não pode e não quer continuar a ir colher em outras épocas os critérios para sua orientação, ela tem de criar em si própria as normas por que se rege". Ela também tem que trazer à superfície as catego rias que permitiram o seu entendimento, é a necessidade de sua autocertificação.

U ma verificação, ainda que rápida do horizonte histórico de três séculos, mostra, de forma inquestionável, um forte processo de mudança. Autorestornaram-se importantes apenas porque fizeram um enorme esforço para captar o que o filosofo G. W. F. Hegel destacou como Zeitgeist. 0 espírito da época caracterizava-se pela busca do entendimento da transição ou, como registra Anthony Giddens (1991), do desencaixe. Entretanto, o fato que diferencia enormemente este tempo é a consciência da aceleração. Novos processos, sobretudo econômicos e políticos, surgem e rumam em um ritmo extraordinário para o futuro. A noção de futuro quase perde o que ela representa, pois, nesses tempos, o moderno é futuro realizado ou realizável em breve.

O processo de mudança deixou para trás, negou ou destruiu estruturas e culturas, isto é, os arranjos sociais antigos, com desfechos variados da simples assimilação à imposição pela violência. 0 fato singular é que hoje podemos trabalhar com a idéia de que o mundo inteiro já fez algum tipo de experiência com a modernidade. Agnes H eller (1999) relata: 
este processo de desconstrução foi tão rápido que mudanças fundamentais foram registradas pela mesma geração... E a velocidade foi constantemente acelerada. No começo do século XX, o mundo pré-moderno ainda não havia sido inteiramente desconstruído nem na Europa; no entanto no final do século, o arranjo social prémoderno já não existe no planeta ${ }^{1}$. (HELLER, 1999:15).

0 ritmo acelerado de mudanças imprimiu à modernidade uma característica bem peculiar. É uma época envolta e dominada por crises. A noção de crise $^{2}$ faz-se presente de forma obrigatória em todos os esforços para compreender a modernidade. Esse termo, do ponto de vista sociológico, é o que melhor caracteriza estes tempos: trata-se de um momento histórico indefinido ou de riscos inquietantes. 0 estado de incerteza influi diretamente na dimensão da vida cotidiana, mas também na dimensão política e econômica. Embora nasçam livres, os homens modernos nascem contingentes, porquanto estão imersos num mundo de relações volatilizadas e precisam encarar o fato de que a liberdade é acompanhada de riscos. Por outro lado, os processos econômicos e políticos são submetidos a um procedimento de calculabilidade das ações na busca de minimizar, ainda que com sucesso questionável, a força da contingência. Assim, não podemosafastar do Zeitgeist a noção de contingência. Maso que ela significa para a modernidade?

A descoberta da contingência exige uma reflexão profunda, certamente, no que diz respeito ao sentimento do medo. Dissolvidas as certezas coletivas que, no 0 cidente, foram dadas pelo Cristianismo, forma-se 0 indivíduo burguês. A subjetividade ganha autonomia, o direito ao pensa-

1 Evidentemente que essa afirmação está circunscrita a uma visão estreita. Poderíamos certamente dizer que, por todo o planeta, estruturas modernas estão em conflito com outras pré-modernas. Acredito que ainda não é tempo de declarar que os arranjos sociais pré-modernos já não existem mais sobre o planeta.

2 Tendo em vista que, de forma genérica, essa noção concerne a um momento ou mesmo a uma situação que, embora ofereça perigos, pode, de modo ambivalente, produzir tanto benefícios quanto prejuízos para o indivíduo ou para a sociedade que por ela passar. 
mento crítico começa a sua caminhada, e o lluminismo é o seu terreno mais fértil. Immanuel Kant (1970) saudou de forma vigorosa esse novo projeto de sociedade e convocou todos os homens a servirem-se de si mesmos, a fazerem uso de seu próprio entendimento, a vencerem a preguiça e a covardia e com isso os incentivou ao sapere aude. 0 esclarecimento é uma estratégia de emancipação, que põe em mãos humanas a realização de um intento que exige do próprio homem algo extraordinário, o esforço para se valer de sua capacidade legisladora. Sobre a consciência do indivíduo repousa o peso do imperativo categórico: "age de tal modo que a máxima da tua vontade possa valer sempre ao mesmo tempo como princípio de uma legislação universal" (KANT, 1999:42). Podemos ver por esse princípio que Kant tenta recuperar valores prático-morais que guiam os homens na esfera pública.

Q uando chama a atenção para esse ponto, Kant, evidentemente, está interessado não, em retornar ao pensamento político clássico, mas na possibilidade de levar o indivíduo burguês para o coração da ação política, desenvolvendo amplamente a autonomia moral. 0 alvo em questão é vencer a heteronomia estabelecida no contexto do jusnaturalismo. A teoria do direito natural está preocupada em juntar os homens, elevando sobre eleso poder do Estado, isto é, submetendo-os a uma liberdade negativa. Para vencer esse argumento heteronômico, Kant mostra uma distinção entre moralidade e legalidade. Norberto Bobbio (2000) explica essa discussão da seguinte maneira: a conduta humana é regulamentada pelas chamadas leis da liberdade e estas se contrapõem às leis da necessidade, que regulam osfenômenos naturais. M asa conduta humana regulada pelas leis da liberdade apresenta duas formas distintas de legislação da ação: a legislação moral e a legislação jurídica.

Não é fácil estabelecer uma distinção entre ação moral e ação jurídica. Para resolver essa questão, Kant, segundo Freitag (1989:05), invoca a noção de dever: "O dever (Pflicht) é compreendido por Kant como sendo a necessidade de uma ação por respeito à lei". Para entender essa questão, 
Bobbio (1984) destaca a existência de três requisitos fundamentais da ação moral: a) ser realizada não para obedecer a uma certa atitude sensível, a um certo interesse material, mas somente para obedecer à lei do dever, b) ser cumprida não por fim, mas somente pela máxima que a determina; c) não ser motivada por outra inclinação que não seja o respeito à lei. Isso que dizer que "para que uma ação seja moral não é suficiente que seja coerente com o dever; é necessário que seja também cumprida pelo dever" (BO BBIO , 1984:54). Analisando essas colocações, diz Bobbio:

a legislação moral é aquela que não admite que uma ação possa ser cumprida segundo inclinação ou interesse; a legislação jurídica, ao contrário, é a que aceita simplesmente a conformidade da lei e não se interessa pelas inclinações ou interesses que a determinaram. $Q$ uando eu atuo de determinada maneira porque este é o meu dever, cumpro uma ação moral; por outro lado, quando atuo de determinada maneira para conformarme à lei, mas ao mesmo tempo porque é meu interesse ou corresponde à minha inclinação, tal ação não é moral, mas somente legal. (BO BBIO, 1984:54)

E conclui: "O que faz da ação conforme a este dever sucessivamente uma ação moral ou jurídica é a diferente motivação da ação: a mesma ação é moral se foi cumprida unicamente por respeito ao dever, é meramente legal se foi cumprida por inclinação ou por calculo" (BO BBIO, 1984:55). Esta discussão é multiaxial, entretanto, o eixo que interessa a esta reflexão é a noção de liberdade, do agir na esfera pública. A noção de liberdade política, para Kant, como afirma Bobbio (2000), está baseada numa idéia de liberdade voltada para al guns princípios liberais e não democráticos (apesar da forte influência do pensamento de Rousseau em suas idéias).

Para entender essa questão, é necessário retomar a reflexão de Benjamin Constant e a sua clássica distinção entre liberdade dos antigos e dos 
modernos. Para esse autor, "o objetivo dos antigos era a partilha do poder social entre todos os cidadãos de uma mesma pátria. Era isso que eles denominavam liberdade. 0 objetivo dos modernosé a segurança dos privilégios privados; eles chamam liberdade às garantias concedidas pelas instituições a esses privilégios" (CO NSTANT, 1980:15). Podemos notar que, na primeira fórmula, é ativa a participação dos homens na esfera pública; na segunda, são as instituições (o Estado) que representam as normas que regulam as relações sociais. N. Bobbio (2000: 105) assinala que Kant entende por liberdade jurídica o poder dar coletivamente leis a si mesmo, isto é, faz coincidir o significado de "liberdade" com "autonomia política".

Há, nessas idéias, uma forte intenção de fazer valer a esfera pública. A liberdade dos modernos (concebida como liberdade negativa) pressupõe um aparelho estatal como fonte da mediação política e social garantindo a todos a felicidade da vida privada. Mas, no contexto do século XVIII e no seu ambiente cultural, econômico e político, já é possível vislumbrar e delinear as formas que o Estado moderno assumiria no 0 cidente, ou na Europa especificamente. 0 pensamento político kantiano marca de certa maneira uma ruptura histórica dentro da própria modernidade. Asforças que trariam a democracia como um regime político estão se estabelecendo; a noção de indivíduo ganha uma nova conotação; definitivamente a competição econômica e a conformação da esfera estatal burocrática como mediadora deixam para trás o sentimento de comunidade. Seguindo a interpretação de Bobbio, Kant ainda sonhou com a liberdade de tipo republicana, movida por um sentimento cívico de responsabilidade com o coletivo, com a ordem social constituída como fruto de consenso, visando à ampliação da esfera de ação com autonomia. U ma ética da ação política garantiria a liberdade. Assim, não haveria necessidade de um regime democrático (no sentido kantiano), que faz da ampliação de órgãos estatais uma maneira de controle e no qual prevalece 0 imperativo das normas (BO BBIO, 2000: 101). 


\section{O Estado, a Técnica e o M edo como Instrumento de Controle Social}

$\mathrm{Na}$ noção de liberdade dos modernos, podemos então encontrar os novos critérios a que a modernidade se submeteu. Lembremos que, para Constant, o objetivo principal dos modernosé a "segurança dos privilégios privados". A preponderância desse preceito certamente enterrou de vez a tentativa kantiana de resgate da tradição da pólisgrega. A democracia moderna criou suas próprias regras de participação, e o Estado M oderno assumiu uma forma ambígua: "de um lado significa um aparato de governo ou de poder e de outro é o sistema social como um todo subordinado a esse governo ou poder" (GIDDENS, 2001:42). Aqui se evidencia um processo de cristalização do Estado que, pelas proposições teóricas de M ax Weber (1991), culmina não somente com a monopolização dos meios de violência e de ad ministração, mas também com a capacidade de reivindicar um poder sobre um território. 0 território geográfico, na definição de Estado em Weber, representa o espaço de ação de uma determinada sociedade; 0 êxito da construção dessa ordem, formando uma unidade interligada, diz Giddens (2001: 47) "refere-se ao Estado-N ação".

O Estado-N ação sobrevive por uma espécie de síntese de uma identidade, o que implica um engano sociológico - na medida em que a nação é compreendida como resultado de uma cultura homogênea, fundada, portanto, numa identidade nacional -, ou seja, o Estado-Nação é o amálgama de um coletivo falso: "o povo". A nação e seu corolário - o nacionalismo sacrificam a existência do gênero humano em nome do gentílico, cristalizando uma série de preconceitos. É por esse meio que temos o "civilizado" e o "bárbaro". Porém, a repercussão maior do desenvolvimento do Estado M oderno, do monopólio legítimo da violência é no âmbito interno. Weber esclarece o que garante a existência do Estado enquanto associação política:

[o Estado existe] na medida em que sua subsistência ea vigência de suas ordens, dentro de um determinado 
território geográfico, estejam garantidas de modo contínuo mediante a ameaça e a aplicação de coação física por parte do quadro administrativo. Uma empresa com caráter de instituição política denominamos Estado, quando e na medida em que seu quadro administrativo reivindica com êxito o monopólio legitimo da violência para realizar as ordens vigentes. (WEBER, 1991: 34)

O território está ligado à idéia de autodeterminação, isto é, a manutenção da ordem interna é uma atribuição exclusiva do aparato de força do Estado, legitimado pelo monopólio da violência. Ainda nesse processo, as relações entre os Estados- $\mathrm{N}$ ações pautam-se apenas por acordos, mas a ordem interna mantém-se pelo estabelecimento de um direito que legitima a coerção física.

Segundo Max Weber, o êxito do Estado em monopolizar a violência deve-se a um processo específico de racionalização, apenas observado no $\mathrm{O}$ cidente. Na sociologia do direito e na sociologia da dominação, Weber identifica os meandros dessa história de "sucesso". 0 aparecimento de um direito racional, afastado, por conseguinte, de todos os efeitos mágicos, tem sua maior expressão na criação de uma doutrina científica que deu origem ao Direito público no 0 cidente. A dominação, no contexto racional, somente adquire vigência quando a ordem estabelecida baseia-se num Direito que possui legitimidade para nomear e delimitar o exercício do mando. Em ambos os casos, está explícito o caráter preponderante da lei sob o princípio da impessoalidade. A lei positiva governa a ação social, e Weber destaca:

um 'Estado' moderno existe em grande medida dessa maneira - como complexo de específicas ações conjunta de pessoas -, porque determinadas pessoas orientam suas ações pela idéia de que existe ou deve existir dessa forma, isto é, de que estão em vigor regulamentações com aquele caráter juridicamente orientado. (WEBER, 1991, p. 9) 
U ma especificidade do processo de racionalização que atingiu as estruturas culturais do 0 cidente é a divisão bem rígida das esferas de poder. 0 quadro administrativo, ao qual Weber faz referência duas vezes na definição de Estado, constitui-se numa estrutura burocrática, baseada na divisão hierárquica dasocupações, na carreira profissional dos funcionários, na rígida separação entre o cargo e os bens pessoais. São muitas as características que Weber aponta no seu estudo da burocracia moderna, porém o que chama a atenção é o fato de somente os funcionários do Estado, do quadro administrativo, exercerem em nome deste a violência. Produzem, assim, uma ordem jurídica capaz de orientar as ações e regulamentar as relações sociais. N essa burocracia está depositada a essência da segurança dosprivilégios privados. 0 monopólio da produção e da aplicabilidade das leis pela esfera estatal prescinde, na modernidade, da ação política na esfera pública. Alcançou-se com sucesso a burocratização das ações sociais nesse contexto e, como na divisão do trabalho, tal qual analisada por Karl M arx, confinaram-se homens e mulheres em um mundo estranhamente fragmentado. 0 indivíduo é obrigado a obedecer determinadas regras porque algumas pessoas acreditam que elas determinam a sua existência. A figura do puritano com seu comportamento econômico representa, para Weber (1999), o paradoxo das conseqüências do desenvolvimento da ordem moderna.

0 desenvolvimento, o que Weber chamou a moderna ordem econômica e técnica, pode levar a humanidade a uma prisão de ferro. Eis 0 paradoxo: as luzes da emancipação são ofuscadas pelo medo. A ordem socioeconômica moderna valeu-se da ciência para criar instrumentos de aceleração do progresso, subverteu a idéia de esclarecimento (aufklärung) e tornou o saber um instrumento técnico, relegando a um plano inferior a autoconsciência. A técnica, para Adorno e Horkheimer (1985: 20), é "a essência desse saber, que não visa conceitos e imagens, nem o prazer do discernimento, mas o método, a utilização do trabalho de outros, o capi- 
tal". A técnica moderna invade o mundo da produção, dominando a sociedade industrial. Capaz de penetrar nos diversos domínios da esfera humana, a técnica conquistou os territórios mais recônditos da ação humana, criando formas institucionais de controle da sociedade.

A técnica, na modernidade, não é apenas um meio de produção, não é apenas uma forma de transformar a natureza em benefícios para a humanidade. N esse processo, ela foi mais além, ajudou a transformar valores-deuso em mercadorias. Nesse caminho, ela incorporou uma ambigüidade, tornando-se a própria razão de ser da modernidade. Anteriormente, Immanuel Kant ainda agitara e incentivara os homens a se valerem da razão para se emanciparem da superstição, a promoverem uma desmagificação ${ }^{4}$ das visões de mundo, a prestarem atenção para os resultados da ciência. Passados três séculos, Adorno e Horkheimer lideram um movimento que, não apenas exige uma reflexão sobre a combinação da razão, do industrialismo, do capitalismo e da modernidade, mas também denuncia uma re-mistificação do mundo em que os meios de emancipação tornamse instrumento de dominação profunda dos homens, valendo-se do terror e do medo. Para esses autores, está claro que o saber tornou-se escravo do poder; a suposta neutralidade da técnica é apenas um artifício que a torna mais eficaz na sua capacidade de dominação. "Tal neutralidade é mais metafísica do que a metafísica. 0 esclarecimento acabou por consumir não apenas os símbolos, mas também seus sucessores, os conceitos universais, e da metafísica não deixou senão o medo abstrato frente à coletividade da qual surgira", denunciam Adorno e Horkeimer (1985: 35).

As análises sobre o esclarecimento não deixam dúvida de que a esperança moderna de poder gozar em segurança os privilégios privados, com a liberdade garantida pelas instituições, transformou-se num terrível mal-es-

4 "D esmagificação" é o termo que Pierucci (2003) emprega para contrapor à noção de secularização. Weber, de forma mais geral, fala em desencantamento do mundo. 
tar. Benjamin Constant acreditou e apostou em uma forma de liberdade mediada pelas instituições; Max Weber mostrou a dominação burocrática que essas instituições passaram a exercer; Adorno e H orkheimer (1985, p. 49) revelaram que "o absurdo desta situação, em que o poder do sistema sobre os homens cresce na mesma medida em que os subtrai ao poder da natureza, denuncia como obsoleta a razão da sociedade racional". A razão tornou-se um instrumento de dominação, e essa transformação é responsável por um retorno à barbárie. Por isso, Adorno e H orkheimer afirmam:

a essência do esclarecimento é a alternativa que torna inevitável a dominação. Os homens sempre tiveram de escolher entre submeter-se à natureza ou submeter a natureza ao eu. Com a difusão da economia mercantil burguesa, o horizonte sombrio do mito é aclarado pelo sol da razão calculadora, sob cujos raios gelados amadurece a sementeira da nova barbárie. (ADORNO \& HORKHEIMER, 1985:49)

$\mathrm{Na}$ dialética do esclarecimento, as noções de civilização e barbárie, progresso e regressão, esclarecimento e ofuscamento aparecem como os principais elementos do diagnóstico sombrio da modernidade por constituírem um forte instrumento de denúncia da razão. O s conceitos, nessa análise, não resistiram à sedução do poder e do progresso e tornaram-se armas potentes para subjugar os homens. Vítimas da sua própria astúcia, os homens são obrigados a se submeterem a fortes mecanismos de alienação, a acreditar numa liberdade que é apenas um mero artifício. As instituições que Ihes prometiam a segurança para gozar os privilégios privados convertem-se em instrumento do medo.

\section{A M odernidade de Risco, Perigo e Medo}

Ao longo do século $X X$, as narrativas da modernidade visavam destacar o progresso em direção ao domínio da natureza; hoje a análise da 
modernidade enfatiza, cada vez mais, a noção de risco e de perigo ${ }^{5}$. Essas noções passaram a ajudar-nos a entender melhor as conseqüências do processo de modernização e suas ambivalências. No campo político, a concentração dos meios de poder fundados no princípio da racionalidade calculadora deu origem a um dos mais efetivos meios de controle social. 0 pensamento social clássico lidou com o despotismo como uma manifestação pré-moderna e acreditou, ou fez acreditar, que, na modernidade, não haveria espaço para o uso arbitrário do poder. Entretanto, a arbitrariedade, valendo-se de meios racionais, impôs-se como um instrumento de controle social. "O totalitarismo é diferente do despotismo tradicional, mas é muito mais aterrador como resultado. 0 governo totalitário combina poder político, militar e ideológico de forma mais concentrada do que jamais foi possível antes da emergência dos estados-nação modernos" (GIDDENS, 1991:17).

Giddens (1991: 17) mostra que os pensadores sociais do século XIX e do início do século XX acreditavam que "a recém-emergente ordem moderna seria essencialmente pacífica". Essa visão os teria impedido de vislumbrar uma conexão perigosa entre organização e inovação industrial com o poder militar. Hoje todos estamos convencidos de que "não apenas a ameaça de confronto nuclear, mas a realidade do conflito militar, formam uma parte básica do 'lado sóbrio' da modernidade" (GIDDENS, 1991: 19. Neste sentido, Giddens assinala que "o século XX é o século da guerra, com um número de conflitos militares sérios envolvendo perdas substanciais de vidas, consideravelmente mais alto do que em qualquer um dos séculos precedentes" (GIDDENS, 1991: 19, grifo nosso). Se, por um lado, podemos notar o potencial de letalidade bélica e de controle social, por outro, não podemos esquecer outras formas de ameaças, como ao próprio indivíduo ou ao meio ambiente. Assim, não podemos deixar de concluir que "o

5 Adiante essas noções serão explicitadas. 
mundo em que vivemos hoje é um mundo carregado e perigoso" (GIDDENS, 1991: 19).

As análises precedentes esclarecem algo importante: a modernidade trocou o sentimento de aventura pelo sentimento do medo. 0 que era segurança tornou-se um instrumento de controle social; o que era confiança no progresso tornou-se uma efetiva ameaça à existência da civilização. Sendo assim, é evidente que estamos no limbo de uma sociedade de risco. Entretanto, como podemos definir o risco? Poderíamos pensar que ele deriva de uma incerteza, de uma impossibilidade de controlar o futuro por meio de um cálculo seguro:

se eu arrisco algo, corro o perigo de perder algo. Não existe nenhum risco sem a valorização positiva de algo, não existe nenhum risco sem algo que alguém possa perder. 0 risco é um acontecimento futuro, um momento esperado ou temido no qual essa perda pode acontecer [... ] um perigo realizado é um desastre, terminando o percurso perigoso. O risco, pelo contrário, é algo que abre uma dada situação e bifurca o percurso da história de forma imprevisível. (BRÜ SEKE, 2001: 36).

A idéia de risco está ligada aos perigos futuros de uma determinada ação (social ou individual), por isso não deixa de ter relação com a idéia de medo. Aristóteles, no livro II da Retórica, afirma: "o medo é uma dor ou uma agitação produzida pela perspectiva de um mal futuro, que seja capaz de produzir morte ou dor". É importante reter a idéia de "agitação", pois este movimento pode ser interpretado como angústia e inscrever-se no eixo das emoções. Na moderna filosofia ocidental, M. Heidegger (1997) julga o fenômeno do medo constitutivo da existência inautêntica, isto é, da existência "lançada no mundo" e abandonada às vicissitudes desse mundo. Como tal, o medo não é um fenômeno temporal parcial, masum modo de ser essencial e permanente. No que se refere à angústia, H eidegger assu- 
me que ela existe pelo simples fato de se estar no mundo, pela situação originária e fundamental da existência humana. Pode-se então dizer que o medo é algo ameaçador, mas que pode ser contornado, removido ou afastado, ao passo que a angústia somente pode ser sentida diante do mundo como tal. Como o homem tem de enfrentar os fatos e os acontecimentos e esses fatos e acontecimentos podem tornar-se ameaçadores, para H eidegger, o medo pode ser considerado uma angústia caída no mundo, inautêntica e oculta a si mesma6.

Q uando nos reportamos à história da modernidade, não podemos deixar de sentir a força de um deslocamento ou, no dizer de A. Giddens, de um desencaixe, momento em que, segundo Habermas, ocorre a formação de um novo arranjo social que quer esquecer o passado, visto que não é mais possível, na modernidade desencantada, alimentar as utopias reconciliadoras. No lugar da comunidade, coloca-se o indivíduo envolto por sua subjetividade. 0 nascimento do eu é, de acordo com Jean-François M attei (2002), a grande contribuição do Cristianismo para a modernidade. Mattei, ao contrário de A. Giddens, não trabalha com a noção de ruptura, ele vai buscar na agricultura a imagem de uma mistura que altera as espécies originais - o enxerto. Para Mattei, a busca da interioridade do homem que marca o pensamento ocidental clássico é herança do Cristianismo, particularmente dos ensinamentos paulinos. $\mathrm{Na}$ sua carta aos colossenses $(3,11)$, Paulo enfatiza: "Aí não há mais grego e judeu, circunciso e incircunciso, bárbaro, cita, escravo, livre, mas Cristo é tudo em todos". $\mathrm{Na}$ sua análise, Mattei (2002: 126) pergunta: "Q ue homem novo é esse que não é mais judeu, grego ou bárbaro, que se retira do espírito do mundo assim como do espírito da cidade para receber, em seu santuário, o Espírito que vem de Deus?". A resposta é a descoberta do homem interior, que se renova na medida em que destrói o "homem exterior".

6 As reflexões sobre o medo aqui apresentadas neste contexto inspiram-se nas idéias recolhidas em Abbagnano (2000: 311). 
Para Mattei, a imagem do enxerto é importante, pois nos ajuda a entender por que a civilização não foi capaz de sublimar a barbárie:

A civilização européia edificou-se lentamente a partir de uma sucessão de enxertos em um núcleo básico inicial, assim como uma pérola cultivada, a partir de um corpo parasita, secreta pouco a pouco suas camadas sob a casca da ostra: o enxerto grego, o enxerto romano sobre enxerto grego e o enxerto agostiniano sobre o enxerto romano formam assim o nácar da Europa cristã que sufocou o elemento inicial sem o destruir (MATTEI, 2002: 132).

Constata-se, de forma inequívoca, que a barbárie não foi deixada fora do umbral da civilização romana, ela também não foi convertida ao Cristianismo, foi a alma individual juntamente com a alma do mundo que foi expulsa da comunidade. N esse movimento de retração, de separação, ocorreu o processo de interiorização, doravante, o bárbaro "estará no interior do eu, encerrado numa caverna ou num túmulo" (M ATTEI, 2002: 146). Para concluir diz Mattei:

poder-se-ia mesmo afirmar que o caráter principal da Modernidade, pelo qual ela se distingue radicalmente da Antiguidade, provém dessa passagem insensível da substancialidade à subjetividade, ou, para dizer numa linguagem menos severa, da passagem da alma ao eu e, ao mesmo tempo, da passagem da exterioridade à interioridade (MATTEI, 2002: 146, grifos do autor).

0 resultado principal deste desdobramento é a afirmação da existência do "eu" universal, mas inteiramente abstrato, privado de substância, vazio e entregue às vicissitudes e às armadilhas da sua autodeterminação. $\mathrm{N}$ a sua reflexão sobre o medo, como vimos anteriormente, Heidegger mostra que a existência "lançada no mundo" põe em jogo o próprio ser-do-ente, no abandono a si mesmo, a sua autodeterminação é o único meio para 
enfrentar os riscos e os perigos da existência inautêntica. Nesse contexto, não há como não pensar em uma existência amparada apenas em uma razão estratégica, na força da razão calculadora e centrada no sujeito. Esta exigência aumenta à medida que o processo de modernização se autonomiza e os riscos sociais e individuais são mais claros no horizonte. U. Backer afirma: "A sociedade de risco não é uma opção que se pode escolher ou rejeitar no decorrer de disputas políticas. Ela surge na continuidade dos processos de modernização autônoma, que são cegos e surdos a seus próprios efeitos e ameaças" (BECK, 1997: 16). Se concordarmos com Beck, concordaremos também com Adorno e H orkheimer e com os perigos da razão instrumental porque eles deixam evidente que o abandono do sujeito ao fluxo da H istória reverte-se num processo de modernização do medo. O brigado a tornar-se senhor da razão, o homem, buscando a máxima dominação, faz mau uso desta, e é nisso que se manifesta a barbárie que permaneceu enxertada na civilização ocidental: o cálculo criminoso é o reflexo do "despotismo interior do sujeito[...]; neste caso seus instintos de violência" (M ATTEl, 2002: 62).

Ao tratar do despotismo interior, M attei chama a atenção para a noção de "barbárie reflexiva". Estando a barbárie interiorizada no sujeito, a razão não escaparia à tentação do uso da violência e do crime como um dos meios eficazes no cálculo da realização dos fins. Sigmund Freud, analisando a expectativa do desenvolvimento das forças técnicas da sociedade, assinala: "é inequívoca a influência exercida sobre as relações sociais da humanidade pelo progressivo controle das forças da natureza. Pois os homens sempre colocam seus instrumentos de poder recentemente ad quiridos a serviço de sua agressividade e usam-nos contra os outros homens"7. A modernidade foi capaz de criar um artifício poderoso no sentido de atrair a violência para a esfera do Estado; o monopólio estatal da violência, com

7 Excerto da XXXV Conferência, que se encontra no volume XXII na Edição Eletrônica Brasileira das O bras Psicológicas Completas de Sigmund Freud. 
toda a ambigüidade que possa carregar, torna-se um fator preponderante na busca da segurança. Explicita Bauman (2003: 30): “o moderno arranjo capitalista - do convívio humano tinha uma forma de Jano: uma face era emancipatória, a outra coercitiva, cada uma voltada para um setor diferente da sociedade... Para dizer de maneira curta e grossa: a emancipação de alguns exigia a supressão de outros".

\section{Ambivalência e Medo}

A discussão levantada por Z. Bauman revela o aprofundamento das ambivalências que se engendraram na modernidade. Partindo do pensamento clássico, Bauman vale-se da imagem imortalizada por Karl M arx, que mostra as pilastras de sustentação da ordem burguesa cheias de cargas explosivas - a fonte de sua própria destruição. M arx afirmou que "essa subversão contínua da produção, esse abalo constante de todo o sistema social, essa agitação permanente e essa falta de segurança distingue a época burguesa de todas as precedentes" (MARX; EN GELS, 2001: 24). Nesse momento o pensamento social experimentava um instante crucial, aquilo que A. Giddens denominou desencaixe, a destruição dos últimos vestígios da comunidade 8 e o nascimento do individualismo. Refletindo sobre esse começo da modernidade, Bauman assume uma posição já conhecida desde 1651, quando T. H obbes publica o Leviatã. Nessa obra, o medo ${ }^{9}$ individual é instituído como fonte do poder estatal. Para H obbes, o governante governa

8 Sobre esse tema, Bauman escreve: "A guerra contra a comunidade foi declarada em nome da libertação do indivíduo da inércia da massa. Mas o verdadeiro resultado - ainda que não dito dessa guerra foi o oposto do objetivo declarado: a destruição dos poderes de fixar padrões e papéis da comunidade de tal forma que as unidades humanas privadas de sua individualidade pudessem ser condensadas na massa trabalhadora" (BAU M AN, 2003, p. 30).

9 "M inha mãe pariu gêmeos, eu, o medo". "O medo foi a única paixão de minha vida". Ribeiro (1999) retirou a primeira frase da autobiografia de $\mathrm{H}$ obbes, que a teria escrita do alto de seus 90 anos; Ribeiro (2004) diz ter retirado a segunda da obra intitulada Prazer do texto, de Roland Barthes. 
pelo temor que inflige a seus súditos, mas não pelo terror, que é um elemento pertencente ao estado de natureza (o homem lobo do homem); o indivíduo que assimilar as regras sociais não terá problemas com o soberano e entrar no Estado é a única esperança de ter uma vida melhor e confortável. Esses três pontos mostram que a filosofia política de $\mathrm{H}$ obbes navega entre a esperança e 0 medo $^{10}$. Aqui é importante assinalar que a esperança está numa vida segura, fugir da morte violenta; significa renunciar à liberdade individual e acreditar numa comunidade artificial, o Estado. Analisando a liberdade dosmodernos, tal qual Constant a havia concebido, Bauman (1998: 10) assegura que "os esplendores da liberdade estão em seu ponto mais brilhante quando a liberdade é sacrificada no altar da segurança".

Esta ambivalência é para Bauman, como intérprete de Freud, a causa do mal-estar da civilização. Diz ele:

A segurança ante a tripla ameaça escondida no frágil corpo, 0 indômito mundo e os agressivos vizinhos chamadospara o sacrifício da liberdade: primeiramente e antes de tudo, a liberdade do indivíduo para a procura do prazer. Dentro da estrutura de uma civilização concentrada na segurança, mais liberdade significa menos mal-estar. Dentro da estrutura de uma civilização que escolheu limitar a liberdade em nome da segurança, mais ordem significa mais mal-estar (BALMAN, 1998: 9).

Como a sociedade moderna optou pela ordem - para poder gozar dos privilégios privados -, ao longo de seu desenvolvimento teve que modernizar concomitantemente os mecanismos técnicose organizacionais como meios de poder. N este processo, percebe-se que o pensamento hobbesiano não foi preterido, a ameaça de utilização da força territorializou a democracia e instituiu o medo como fonte da manutenção da ordem.

Anteriormente nos referimos a uma passagem da obra de Bauman para mostrar que a emancipação significa uma supressão. Podemos ver aí 
uma tensão entre as forças sociais da modernidade. Bauman buscou em Freud o entendimento do mal-estar da modernidade, mas foi em $\mathrm{M}$ arx que ele recolocou o conflito social de classes. Nesse ponto, o foco volta-se para o sistema de controle (o Estado policial), a ordem social depende exclusivamente dele. Para situar essa discussão Bauman diz que a modernidade valeu-se do modelo panóptico ${ }^{11}$. Na época da vigilância contínua, "O modelo panóptico de poder prendia os subordinados ao lugar, aquele lugar onde podiam ser vigiados e punidos por qualquer quebra de rotina. Mas também prendia os supervisores ao lugar, aquele de onde deviam vigiar e administrar a punição" (BAU MAN, 2003: 35). A evolução desse processo mostrou uma mútua dependência: "Os governados dependiam dos governantes, estes não deixavam depender daqueles. Para o bem ou para mal os dois lados estavam amarrados entre si e nenhum deles podia com facilidade sair do impasse - por difícil ou repulsivo que fosse" (BAUMAN, 2003: 35). A isso Bauman denominou a "era do engajamento", o poder e a riqueza juntamente com a força de trabalho compunham um quadro de conflitos, mas nenhum doslados podia dar-se ao luxo da separação. Assim, "passou-se muito tempo até que os dois lados, em muitas tentativas e erros, aprendessem essa verdade. U ma vez aprendida a verdade, a inconveniência e 0 alto e crescente custo do poder panóptico (e, em geral, pela dominação pelo engajamento) ficaram óbvios" (BAU M AN , 2003: 36)12. Ainda no contexto da formação do capitalismo industrial, Marx havia apostado no turbilhão, no conflito desencadeado pelo sistema de poder e da exploração capitalista - "onde tudo que é sólido desmancha do ar" - como uma fase

11J. Bentham, filósofo inglês(1748-1832), criou uma figura arquitetônica que deveria ser usada para a construção de um presídio: em torno de uma torre central, constroem-se em círculos as células prisionais, que devem ter janelas amplas de vidro através das quais um vigia pode com a máxima eficiência observar toda a movimentação dentro do prédio. Essa figura - o panóptico - é retomada e analisada por M. Foucault em sua obra Vigiar e Punir.

12 Em um outro contexto Brüseke (1996), ao analisar essa relação referiu-se ao proletariado como “o aliado rebelde". 
necessária no processo de mudança para uma vida verdadeiramente segura, livre dos conflitos violentos provocados pela emancipação seletiva da modernidade inicial. M as a destruição e a reconstrução após períodos prolongados de guerra, no século XX, anunciaram a obsolescência do modelo do panóptico e o advento de uma modernidade líquida (BAU M AN , 2001), o momento em que instituições e valores perdem sua força e em que aumenta a perda do sentido, a insegurança e o mal-estar. ${ }^{13}$

A crise do welfare state, a partir dos anos de 1970, significou o início de um novo processo, que Bauman denominou de desengajamento. U ma dissolução abrupta da velha aliança marcou o início de uma era em que as palavras de ordem são: "aceleração", "flexibilização" e "desregulamentação". A eficiência do panóptico é substituída pela idéia de incerteza. Aqui a secessão dos bens-sucedidos constitui um fosso profundo. A distância cada vez maior traduz-se em indiferença. A dominação não prima mais pela busca da obediência direta:

os detentores do poder não têm o que temer e assim não sentem necessidade das custosas e complicadas 'fábricas de obediência' ao estilo panóptico. Em meio à incerteza e à insegurança, a disciplina anda e se reproduz por conta própria e não precisa de capataz para supervisionar seu abastecimento constantemente atualizado (BAUM AN, 2003: 42).

Vista por esse ângulo, a modernidade líquida parece concluir de uma vez o inexorável abandono do indivíduo. P. Rosavalon e J.-P. Fitoussi (1997) assinalam que a emancipação dos indivíduos, isto é, sua autonomia faz deles portadores de direitos, mas, por outro lado, submerge-os no mar de insegurança crescente, obrigando todos a serem responsáveis pelo futuro e

13 Referindo-se a essa questão, M attei (2002, p. 140) assinala: "Édipo podia ainda contar com Antígona para guiá-lo em segurança a Colono; o Homem moderno tem apenas seu analista, depois de muitos silênciose recusas, para reconduzi-lo a si". 
a darem sentido a uma vida que não é mais predeterminada a partir de fora. Assim, a razão que permite o cálculo do risco de suas ações joga-os ao abandono da sua auto determinação num mundo sem referências. Sem as tais referências sociais, a ordem perde coerência, e "o tipo de incerteza, de obscuros medos e premonições em relação ao futuro que assombram os homens e as mulheres no ambiente fluido e em perpétua transformação em que as regras do jogo mudam no meio da partida sem qualquer aviso ou padrão legível, não une os sofredores: antes os divide e os separa" (BAUMAN, 2003: 48).

Com a cisão do mundo não apenas entre pobres e ricos e com a destruição dos últimos vestígios de identidade de classe, formada no âmbito da disciplina, esfumou-se a eficiência do controle social: "a ordem global precisa de muita desordem local 'para não ter o que temer'", afirma Bauman (2003: 96). N este ponto é importante situar a teoria sociológica de Bauman. O s grupamentos sociais estão sendo divididos em ricos e pobres. O s ricos são homens e mulheres globalizados, desenraizados, desengajados, com trânsito relativamente livre pelos espaços globalizados pelo capitalismo; os pobres estão cada vez mais isolados em guetos. A guetificação é paralela e complementar à criminalização da pobreza. 0 gueto e as prisões ${ }^{14}$ são uma forma de força "para prender os indesejáveis ao chão", mantendo-os confinados e imobilizados. 0 perigo, alerta Bauman (2003: 111), é que "um gueto não é um viveiro de sentimentos comunitários. É, ao contrário, um laboratório de desintegração social, atomização e de anomia".

N esse contexto de desintegração social, Bauman destaca o abandono do papel de regulação normativa do Estado- $N$ ação. As tarefas de promover a integração social entregues a forças sobre as quais ele não mais tem jurisdição. 0 policiamento ainda é, dentro do território administrado, a única função deixada nas mãos dos governos dos Estados. Vale ressaltar: a 
polícia é o último órgão que adentra o gueto. 0 contato com os desintegradosfaz-se, portanto, sob o domínio da violência.

Esperar que o Estado, se chamado ou pressionado adequadamente fará algo palpável para mitigar a insegurança da existência não é muito mais realista do que esperar o fim da seca por meio de uma dança da chuva. Parece cada vez mais claro que o conforto de uma existência segura precisa ser procurado por outros meios. A segurança, como todos os outros aspectos da vida humana num mundo inexoravelmente individualizado e privatizado, é uma tarefa que toca a cada indivíduo (BAUMAN, 2003: 102).

0 trabalho de Bauman tem por objetivo mostrar a constituição de uma modernidade em torno de um eixo do qual se podiam calcular os avanços e os progressos, mas também sobre o qual as ciências sociais podiam ainda exercer uma análise crítica e esclarecedora. Na modernidade fluida, a elite intelectual teria renunciado a esse papel, mas teria encontrado na discussão multiculturalista uma forma de se colocar contra a intolerância cultural. $\mathrm{Na}$ interp retação de Bauman, essa atitude é mais uma forma de esconder a condescendência com o afastamento da "agenda pública da questão da privação material. Fonte profunda de toda desigualdade e injustiça" (BAU MAN, 2003: 96).

O diagnóstico da modernidade líquida apresentado por Bauman parece complementar a constatação de M attei de que a barbárie é a outra face de uma moeda chamada civilização. As mudanças profundas no sistema social, com forte repercussão na cultura e na política, parecem revelar a presença do poder de destruição. Teme-se o monopólio da violência pelo Estado-N ação, mas é muito mais temerosa a violência difusa que parte de estruturas capilares da sociedade (o crime organizado, por exemplo). N esse contexto, em que há uma intensa modernização do medo, uma 
cotidianização do medo, quais seriam as chances de se formarem estruturas políticas voltadas para a segurança? É evidente o grau de dramaticidade do diagnóstico da modernidade efetuado por Adorno e Horkheimer na Dialética do Esclarecimento (1985). A constatação de uma lógica da decadência dentro da modernidade aponta para uma desordem sempre iminente. Vale reter dessa análise, que obscurantismo esteve sempre presente na $\mathrm{H}$ istória. Ao lançar-se em busca de esclarecimento, a humanidade merguIha na escuridão, desorientada pelo ofuscamento provocado por seu próprio progresso. Em Adorno e Horkheimer (1985), todas as possibilidades resultariam na máxima: "A própria razão destrói a humanidade que ela possibilitou" (HABERMAS, 1990: 113). Para alguns autores-os defensores do pós-modernismo -, essa constatação permite compreender uma modernidade que se autonomizou. Isso implicaria dispensar o horizonte conceitual da razão ocidental, considerando que as premissas do lluminismo estão mortas, tendo restado somente as suas conseqüências.

Assim, a modernidade tornou-se obsoleta, executando apenas as leis funcionais da economia e do Estado, da técnica e da ciência. A exaustão da cultura moderna levou-a a um estado de cristalização, isto é, tudo o que poderia ser desenvolvido já foi alcançado. Esse horizonte de despedida é o traço marcante do movimento pós-modernista que encontrou, nos anos de 1950-1960, um solo fértil.

J. Habermas chama a atenção para o fato de que a crítica autodestruidora de Adorno e Horkheimer "acaba deixando em aberto a contradição performativa de uma critica ideológica que se ultrapassa a si própria, que já não faz questão de se superar teoricamente" (HABERMAS, 1990: 127). Da mesma forma, ao apreciar a denúncia totalitária da razão, feita pelos autores da Dialética do Esclarecimento, Mattei identifica uma contradição importante. Diz ele:

resulta desta constatação irremediável que Tudo, em um único e só sentido é bárbaro, o que tem como conseqüência, por uma dedução igualmente bárbara, 
que a crítica total do todo a que se entregam Horkheimer e Adorno ainda faz parte da barbárie. É preciso concluir então, por uma espécie de redução ao absurdo, que a barbárie nada mais é que o processo de autodestruição da razão, a qual, criticando esse processo de destruição, só faz reforçá-lo para engendrar ad libitum a espiral infinita da barbárie (MATTEI, 2002: 56).

Nessa discussão, não é necessário partir definitivamente para uma sombria conclusão. Certamente mudanças profundas se estão descortinando à nossa frente, mas é preciso um esforço para apreender as suas tensões e ambivalências. Estão claros os fortes deslocamentos que marcam uma diferenciação dentro da modernidade. 0 próprio dinamismo da modernidade provocou um processo de autonomização, despertando o sentimento de incerteza. U. Beck denomina este momento de "modernização reflexiva" ou de autoconfrontação. Entretanto, é importante assinalar que, a partir dessa constatação, o conceito de sociedade de risco passa a orientar o diagnóstico de um novo estágio da modernidade. Nesse sentido, tanto a apreciação de Beck como a de Giddens mostram que é possível restabelecer a força crítica da razão.

\section{Conclusão}

O risco, talvez despertado pelo sentimento do medo, mobiliza a sociedade a articular com mais cuidado os seus instrumentos de intervenção, desde a natureza até a organização social. Precisamente nesse contexto ganha relevo a noção, defendida por $\mathrm{H}$ abermas, de esfera pública, que, em última instância, representa um instrumento, um fórum de conteúdo nãoestatal, cuja base é um público que julga, que tem a vantagem de trazer à baila a questão da legitimação discursiva do Estado. B. Constant queria a 
intervenção das instituições para a garantia do gozo do privilégio da liberdade individual, mas o aprofundamento do processo de individualização e 0 superdimensionamento das instituições estatais revelaram a face cruel e temerosa do totalitarismo na política. U. Beck, A. Giddens, J. Habermas, J. F.M attei e Z. Bauman, cada um por seu ângulo próprio, nem sempre compartilhando as mesmas estratégias teóricas, voltam seus interesses para a reconstrução de uma esfera pública política orientada pelo princípio do pluralismo. Mattei (2002, p. 288), por exemplo, chama a atenção para o fato de as democracias modernas estarem reduzindo o cidadão à pura virtualidade do sujeito jurídico, o que resulta num declínio da participação na vida pública e num retraimento do espaço público. Por outro lado, H abermas (2002) tem desenvolvido uma reflexão no sentido de redirecionar o estatuto da razão na modernidade tardia.

O princípio dialógico da razão é, para Habermas, o fator essencial na construção de uma nova ordem social, neste momento da história da modernidade, em que necessariamente terão de estar presentes a pluralidade, a partilha de poder, o exercício da cidadania, emoldurada por uma esfera pública de inclusão e de efetivas arenas de deliberação. Para Beck, Giddens, Mattei e Bauman, e, sobretudo, para Habermas, não dá para fugir da incerteza, do perigo e de uma atmosfera de medo, sem assegurar a existência de uma cultura política que permita integrar livremente os membros de uma sociedade em uma associação voluntária, organizada sob princípios jurídicos universais. Ao que parece, todos querem dizer que nos devemos voltar para a política, ou continuaremos a presenciar a manifestação da barbárie como a principal marca da modernização do medo. 
Ambivalence and Fear: facets of the risks in Modernity

\begin{abstract}
In the diagnosis of the modernity, uncertainty and insecurity - and therefore the fear - they are present elements. Leaving of that verification, this work has for objective to describe the ambivalent effects of the fear on the contemporary society. In that attempt, the support of several social theories is looked for that, although they don't focus the fear, they show the constant risks of the modernization process in a certain way. $\mathrm{O} n$ the other hand, that allows to separate the social critic, that it still tries to continue thinking the modernity with base about the conceptual premises of the western reason, of another one, that for your own fatigue proclaims your self-destruction. Understands each other here that to say good-bye of the reason and to consider the autonomous movement of the modernity is to do a process that just guarantees the modernization of the fear to appear.
\end{abstract}

Keywords: Modernity. Risk. Fear

\title{
Referências
}

ABBAGNAN O, Nicola. Dicionário de Filosofia. São Paulo: Martins Fontes, 2000. ADO RN O, Theodor W.; HORKHEIMER, Max () Dialética do Esclarecimento. 2a ed. Rio de Janeiro: Jorge Zahar Editores, 1985.

BAUMAN, Zygmund 0 Mal-Estar da Pós Modernidade. Rio de Janeiro: Jorge Zahar Editores, 1998.

. Em Busca da Política. Rio de Janeiro: Jorge Zahar Editores, 2000.

. A Modernidade Líquida. Rio de Janeiro: Jorge Zahar Editores, 2001.

. Comunidade: A Busca por Segurança no M undo Atual. Rio de Janeiro: Jorge Z̄ăhar Editores, 2003.

BO BBIO , Norberto D ireito e Estado no Pensamento de Emanuel Kant Braślia: UNB,1984.

.Teoria Geral da Política: A Filosofia e a Lição dos Clássicos. Rio de Janeiro: Campus, 2000.

BRÜ SEKE, Franz J A Lógica da Decadência. Belém: Editora Cejup, 1996. $\overline{2} 001$.

A Técnica e os Riscos da Modernidade. Florianópolis: Editora da UFSC, 
DELU MEAU Jean História do Medo no 0 cidente: 1300-1800. São Paulo: Companhia das Letras, 1989.

FREITAG, Bárbara A Q uestão da Moralidade: da Razão Prática de Kant à Ética Discursiva de Habermas. Tempo Social, Rev. Sociol. USP, São Paulo, v. 1, n.ำ 2, p. 7-44, 2으, 1989.

FREUD, Sigmund. Novas Conferências Introdutórias Sobre Psicanálise - Conferência XXXV. In: FREUD, Sigmund. Edição Eletrônica Brasileira das O bras Psicológicas Completas. Rio de Janeiro: Imago. 1 CD-ROM.

GIDDENS, Anthony. As Conseqüências da Modernidade. São Paulo: Unesp, 1991. HABERMAS, Jürgen. 0 Discurso Filosófico da Modernidade. Lisboa: Publicações Dom Quixote, 1990. $\overline{2002}$.

A Inclusão do O utro: Estudos de Teoria Política. São Paulo: Edições Loyola,

HELLER, Agnes U ma Crise Global da Civilização: O s Desafios Futuros. In: A Crise dos Paradigmas em Ciências Sociais e os Desafios para o Século XXI. Rio de Janeiro: Contraponto, 1999.

KANT, Immanuel Crítica da Razão Prática. Lisboa: Edições 70, 1999.

MATTEI, Jean-François A Barbárie Interior: Ensaio sobre o I-M undo Moderno. São Paulo: Unesp, 2002.

PIERUCCI, Antonio Flávio 0 Desencantamento do Mundo: Todos os Passos do Conceito em Max Weber. São Paulo: Editora 34, 2003.

RIBEIRO, R. Janine Hobbes: O Medo e a Esperança. In: WEFFO RT, F. (O rg.) Os Clássicos da Política. São Paulo: Ática, 1993.

RIBEIRO, R. Janine Ao Leitor sem Medo: Hobbes Escrevendo contra seu Tempo. 2a. Ed. Belo Horizonte: Editora da UFM G, 1999.

ROSAVALO N, Pierre; FITO U SSI, Jean-Paul (). La Nueva Era de las Desigualdades. Buenos Aires: M anantial, 1997.

WACQUANT, Loïc A Aberração Carcerária à Moda Francesa. Dados, Rio de Janeiro, v. 47, n.으 02, p. 215-232, 2004.

W EBER, M ax Economia e Sociedade: Fundamentos da Sociologia Compreensiva. Brasília: UNB, 1991.

W EBER, Max A Ética Protestante e o Espírito do Capitalismo. 13a ed. São Paulo: Pioneira, 1991.

Recebido: 03/04/2008

Aceite final: 09/06/2008 